\title{
Genetic variants in CYP2A6 and UGT1A9 genes associated with urinary nicotine metabolites in young Mexican smokers
}

\author{
Gissela Borrego-Soto ${ }^{1}$ Y Yadira X. Perez-Paramo ${ }^{2}$ Gang Chen ${ }^{2}$. Sandra K. Santuario-Facio ${ }^{1}$. \\ Jesus Santos-Guzman $\mathbb{D}^{1} \cdot$ Rodolfo Posadas-Valay $^{3} \cdot$ Fatima M. Alvarado-Monroy $^{1} \cdot$ Isaias Balderas-Renteria ${ }^{4}$.

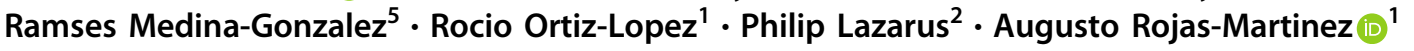

Received: 12 April 2019 / Revised: 19 December 2019 / Accepted: 7 January 2020 / Published online: 21 January 2020

(c) The Author(s), under exclusive licence to Springer Nature Limited 2020. This article is published with open access

\begin{abstract}
Nicotine is the major pharmacologically active substance in tobacco. Several studies have examined genotypes related to nicotine metabolism, but few studies have been performed in the Mexican population. The objective was to identify associations between gene variants in metabolizing enzymes and the urinary levels of nicotine metabolites among Mexican smokers. The levels of nicotine and its metabolites were determined in the urine of 88 young smokers from Mexico, and 167 variants in 24 genes associated with nicotine metabolism were genotyped by next-generation sequencing (NGS). Trans-3'hydroxy-cotinine (3HC) and 4-hydroxy-4-(3-pyridyl)-butanoic acid were the most abundant metabolites (35 and 17\%, respectively). CYP2A6*12 was associated with $3 \mathrm{HC}(p=0.014)$. The rs 145014075 was associated with creatinine-adjusted levels of nicotine $(p=0.035)$, while the $\operatorname{rs} 12471326$ (UGT1A9) was associated to cotinine- $N$-glucuronide $(p=0.030)$. CYP2A6 and UGT1A9 variants are associated to nicotine metabolism. 4HPBA metabolite was an abundant urinary metabolite in young Mexican smokers.
\end{abstract}

\section{Introduction}

Smoking is a risk factor for six of the eight leading causes of death in the world, including lung cancer [1]. The World Health Organization (WHO) estimates that without

Supplementary information The online version of this article (https:// doi.org/10.1038/s41397-020-0147-4) contains supplementary material, which is available to authorized users.

$\triangle$ Augusto Rojas-Martinez

augusto.rojasmtz@tec.mx

1 Tecnologico de Monterrey, Escuela de Medicina y Ciencias de la Salud, Monterrey, Mexico

2 Department of Pharmaceutical Sciences, College of Pharmacy and Pharmaceutical Sciences, Washington State University, Spokane, WA, USA

3 Facultad de Medicina, Centro Universitario de Salud, Universidad Autonoma de Nuevo Leon, Monterrey, Mexico

4 Facultad de Ciencias Quimicas, Universidad Autonoma de Nuevo Leon, Monterrey, Mexico

5 Centro de Investigación y Desarrollo en Ciencias de la Salud, Universidad Autonoma de Nuevo Leon, Monterrey, Mexico adequate controls, tobacco-related deaths will increase to more than 8 million in the year 2030, particularly in developing countries [2]. In Mexico, about 10 thousand new cases of lung cancer are diagnosed every year and the majority are related to smoking (71\%). Lung cancer ranks seventh in incidence among cancer sites and is first in mortality, and about 8000 Mexicans die from this neoplasm each year [3].

Nicotine is associated with tobacco addiction. Most of the nicotine metabolism takes place in the liver [4]. Approximately $80 \%$ of nicotine metabolism in the body is by phase I metabolism to cotinine and then to trans-3'hydroxy-cotinine (3HC), mainly by the enzyme CYP2A6. Nicotine, cotinine and $3 \mathrm{HC}$ are all glucuronidated in phase II metabolism by the glucuronosyltransferase (UGT) enzymes to render nicotine- $N$-glucuronide (nicotine-Gluc), cotinine- $\mathrm{N}$-glucuronide (cotinine-Gluc) and $3 \mathrm{HC}-\mathrm{O}$-glucuronide (3HC-Gluc; Fig. 1), resulting in more polar molecules that are easily excreted in the urine $[5,6]$. Also, nicotine and cotinine are oxidized to nicotine- $N$-Oxide and cotinine- $N$-Oxide by flavin monooxygenases enzymes (FMOs) [7], and it is believed that 4-oxo-4-(3-pyridyl) butanoic acid (4HPBA) is formed by the hydroxylation of nicotine by the CYP2A6 enzyme $[8,9]$. 
<smiles>O=C(O)CCC(=O)c1cccnc1</smiles>

4-Hydroxy-4-(3-pyridyl)butanoid acid (4HPBA)<smiles>CCC</smiles><smiles>CN1CCC[C@H]1c1cccnc1</smiles>

Nicotine UGT2B10
UGT1A4

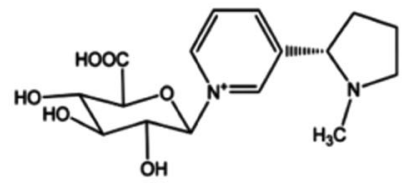

Nicotine-N-glucuronide<smiles>C[N+]1(O)CCC[C@H]1c1cccnc1</smiles>
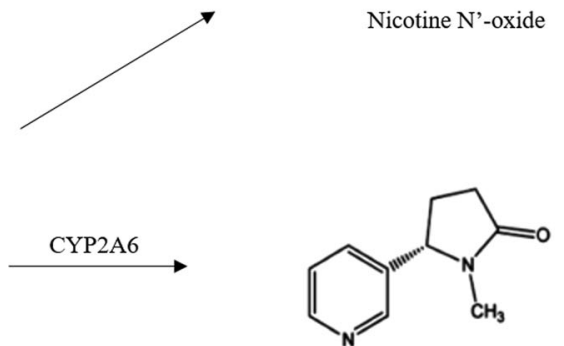

$$
\text { Cotinine }
$$

UGT2B10 UGT1A4

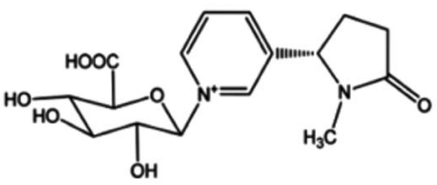

Cotinine-N-glucuronide

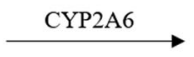<smiles></smiles>
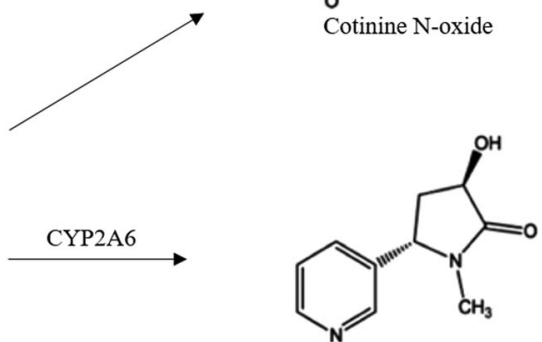

Trans-3'-hydrocycotinine (3HC)

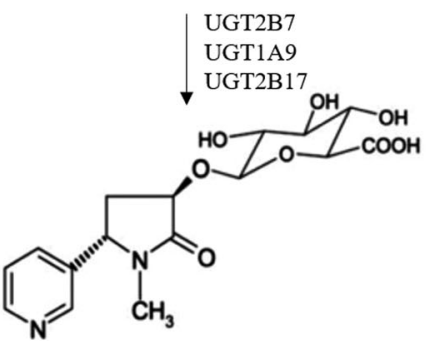

Cotinine-3'-O-glucuronide

Fig. 1 Schematic of major nicotine metabolites (adapted from Perez-Paramo et al. [7]).

Enzymes of nicotine metabolism are highly polymorphic and their genetic variants can cause differences in enzyme activity [7, 10-16]. This may translate into inter-individual differences in the concentration of nicotine in the body and to differences in the number of cigarettes consumed by smokers [17]. For example, $C Y P 2 A 6$ reduced activity gene variants are associated with reduced lung cancer risk in smokers $[18,19]$ and nicotine dependence $[20,21]$ in different populations. While this variants are associated to increased risk for tobacco-related cancers in humans [22-24], they also can affect smoking-frequency, nicotine clearance, and data interpretation of tobacco use [25]. It has been reported that among Mexican smokers between 18 and 35 years, the average number of cigarettes consumed is $1-5$ per day and less than half (37\%) smoke daily [26]. This is considerably less than that observed in other populations. For example, about $76 \%$ of U.S. smokers consume tobacco every day and $40 \%$ of them smoke more than 10-19 cigarettes per day [27]. African American, Caucasians, and Latino subjects older than 25-years-old smoke an average of 9.7 cigarettes per day, and $88 \%$ of them report daily smoking for 6 months or more [28].

Single nucleotide polymorphisms (SNPs) have been associated with the metabolism of nicotine in several ethnic groups, but studies in Mexicans are still scarce [21, 29]. The objective of the present study was to determine whether associations exist between genetic variants in nicotine metabolizing enzyme genes and the concentration of urinary metabolites of nicotine in Mexican smokers.

\section{Material and methods}

\section{Study population}

The study protocol was approved by the Ethics Committee of the School of Medicine and the University Hospital of the Universidad Autonoma de Nuevo Leon (code BI12-005) and ethical standards of the Declaration of Helsinki were followed. Questionnaire data and samples were collected from 88 university students from the northeast region of Mexico. This $n$ was adapted to the number of cells available for NGS in the TrueSeq Custom amplicon kit (Illumina Inc.). Inclusion criteria included being of ages 18-35 years and having smoked more than five cigarettes in the last 3 days. Informed consent was provided by all subjects. Exclusion criteria included liver or kidney disease and pregnancy. Participants signed an informed consent letter, answered a questionnaire about socio-demographic data and their smoking exposure, and provided $5 \mathrm{~mL}$ of peripheral blood anticoagulated with EDTA and $50 \mathrm{~mL}$ of urine. Samples were transported to the laboratory at $4{ }^{\circ} \mathrm{C}$ within 3 $\mathrm{h}$ after sample collection. Genomic DNA was extracted with the TSNT technique (lysis buffer: 2\% Triton, 1\% SDS, 
$100 \mathrm{mM} \mathrm{NaCl}, 10 \mathrm{mM}$ Tris-HCl, $\mathrm{pH}$ 8.0), followed by phenol-chloroform extraction. Urine was aliquoted, and samples stored at $-20^{\circ} \mathrm{C}$ until analysis.

\section{Quantification of urine nicotine metabolites}

Nicotine metabolites were examined using an Acquity liquid chromatography_tandem mass spectrometer (LC-MS/MS system) (Waters Corporation, Milford, MA) as described by Chen et al. [15]. Quantification was performed for the following urinary metabolites: nicotine, nicotine- $N$ '-Oxide, nicotine-Gluc, cotinine, cotinine-Gluc, cotinine- $N$-Oxide, 3HC, 3HC-Gluc and 4HPBA. Urinary creatinine was measured as a control for urine secretion and for normalization of nicotine metabolite levels between specimens [15]. To corroborate measurements, repeat testing was performed for $15 \%$ of all samples, chosen randomly. The limit of quantitation (LLOQ) of all metabolites are shown in the Table S1. The investigators who performed the phenotyping analysis were blinded to all demographic and genotyping data corresponding to the individual subjects including levels of smoking.

\section{Quantification of plasma cotinine}

Quantification of plasma cotinine was performed in duplicate by ELISA (Calbiotech Inc., CA). The assay's lower limit of quantitation (LLOQ) was $0.44 \mathrm{ng} / \mathrm{mL}$.

\section{Genotyping by next-generation sequencing (NGS)}

A custom panel was designed to sequence 384 genetic variants in 52 genes related to xenobiotic metabolism (Table S2), which included 167 genetic variants in 24 genes associated with nicotine metabolism. Specific oligonucleotides were designed using Illumina's Design Studio program (Illumina Inc., San Diego, CA) and the quality and the Illumina staff verified feasibility of their design. A group of 88 subjects who smoked more than five cigarettes in the last 3 days were included. To confirm their tobacco use, plasma cotinine was measured for each subject, with plasma cotinine concentrations ranged between 2.4 and $500 \mathrm{ng} / \mu \mathrm{L}$. DNA quality and concentrations were evaluated using a Nanodrop 8000 spectrophotometer (260/280 absorbance ratio $\geq 1.8$; Thermo Scientific, Wilmington, DE). NGS libraries were amplified using $250 \mathrm{ng}$ of genomic DNA as template and the Truseq Custom amplicon kit in an Eppendorf EP Master Faster thermocycler (Foster City, CA). The quality of the libraries were evaluated in an Agilent 2100 Bioanalyzer (Santa Clara, CA) and were standardized according to the manufacturer's instructions. Libraries were adjusted to a concentration of $12 \mathrm{pM}$ and verified using the Quant-iT Picogreen kit (Thermo Scientific). A pool of libraries from 88 subjects was generated and added to the cartridge MiSeq reagent kit V2 (Illumina Inc.) and was sequenced using the platform MiSeq by Illumina (150 bp paired-end reads) (Illumina Inc.). The variant call format files (VCFs) of each sample were visualized in the Variant Studio software (Illumina Inc.).

\section{CYP2A6*12 genotyping}

CYP $2 A 6^{*} 12$ is a variant resulting from a translocation between the $C Y P 2 A 6$ and $C Y P 2 A 7$ genes generated by a $C Y P 2 A 6 / C Y P 2 A 7$ hybrid formed by exons $1-2$ of the CYP2A7 gene and exons 3-9 of the CYP2A6 gene; this causes the loss of 10 amino acids and reduced $C Y P 2 A 6$ activity [30]. The genotyping of $C Y P 2 A \sigma^{*} 12$ was developed by the method described by Oscarson et al. [30], with small variations. The process was carried out in two steps (PCR1 and PCR2). In PCR1, a common region of CYP $2 A 6^{*} 1$ (wild type) and CYP1A6* 12 (variant) of $2.3 \mathrm{~kb}$ was amplified using $100 \mathrm{ng}$ of DNA in each reaction. The reaction mixture was incubated with GoTaq Green Master Mix (Promega) and $2.5 \mu \mathrm{M}$ of the primers 2A-F (5'GCACCCCTCCTGAGGTACCAC-3') and 2A6ex3R1 (5'GTCCCCTGCTCACCGCCA- $3^{\prime}$ ) in a final volume of $10 \mu \mathrm{L}$. The PCR program started with denaturation at $95^{\circ} \mathrm{C}$ for $1 \mathrm{~min}$, followed by 35 cycles of denaturation at $95^{\circ} \mathrm{C}$ for $15 \mathrm{sec}$, alignment at $60^{\circ} \mathrm{C}$ for $20 \mathrm{~s}$, extension at $72^{\circ} \mathrm{C}$ for $1 \mathrm{~min}$ and final extension to $72^{\circ} \mathrm{C}$ for $7 \mathrm{~min}$. The reaction mixture for PCR2 is a specific allele, the primer 2A6ex1 anneals the exon 1 from $C Y P 2 A 6$ gene and the primer 2A7ex1 anneals the exón 1 from $C Y P 2 A 7$ gene. This PCR identifies the wild type allele and the chimeric CYP2A6/ CYP2A7 allele (respectively), both generate an amplicon of approximately $1.5 \mathrm{~kb}$. PCR 2 was carried out with $1 \mu \mathrm{L}$ of a 1:100 dilution of the PCR1 product, GoTaq Green Master Mix (Promega), $50 \mu \mathrm{M}$ of sense primers (2A6ex1: 5'AACACAGAGCAGATGTACA-3' or 2A7ex1: 5'-AACA CAGAGCACATATGTG-3') and $50 \mu \mathrm{M}$ of antisense primers (5'-CGCTCCCCGTT-GCTGAATA-3') in a final volume of $10 \mu \mathrm{L}$. The PCR program started with a denaturation at $95^{\circ} \mathrm{C}$ for $1 \mathrm{~min}$, followed by 30 cycles of denaturation at $95^{\circ} \mathrm{C}$ for $15 \mathrm{~s}$, alignment at $60^{\circ} \mathrm{C}$ for $20 \mathrm{~s}$, extension at $72{ }^{\circ} \mathrm{C}$ for $1 \mathrm{~min}$ and a final extension at $72{ }^{\circ} \mathrm{C}$ for $7 \mathrm{~min}$. The products were stained with ethidium bromide and visualized in $1.2 \%$ agarose gels.

\section{Data analysis}

Total nicotine metabolite levels, or "equivalents" (Total-Nic$\mathrm{Eq)}$ present in each urine sample were determined as the sum of the $\mathrm{uM}$ concentrations of nicotine, nicotine-Gluc, nicotine- $N$ '-Oxide, cotinine, cotinine-Gluc, cotinine- $N$-Oxide, 3HC, 3HC-Gluc and 4HPBA. The percentage of each analyte in the Total-Nic-Eq and as creatinine-normalized levels 
was calculated based on the equation: $C(\mu \mathrm{M}) /[$ Total-Nic-Eq $(\mathrm{uM})] \times 100$, where " $C$ " is the total urinary metabolite concentration. R package (R-project.org) was used to produce the correlation matrix and Pearson analyses to assess relationship among metabolites. Non parametric Spearman correlation was used to compare urinary and plasma cotinine levels with GraphPad Prism software. To describe the study population, we used basic descriptive statistics. For the analysis of the NGS data, The Human Genome Build construct (hg19) was used as a reference [GRCh38.p12. Homo Sapiens (human). Genome Reference Consortium (December 2017). RefSeq assembly: GCF_000001405.38]. The alignment and the variant calling were done with the Miseq Reporter TruSeq Amplicon (Illumina Inc.). The variants were identified and visualized using Variant Studio software (Illumina Inc.), and the data filtering pipeline was as follows: $\mathrm{Q}>30$, quality of the readings $>100$, depth $>60$, and allelic frequency $>25 \%$. For the gene and metabolite analysis, the variances between groups were different and a Mann-Whitney test for STATA (StataCorp. 2019. Stata Statistical Software: Release 15. College Station, TX: StataCorp LLC) was used. Significance level for $p$-values was set at 0.05 or less.

\section{Results}

Of the 88 subjects recruited into this study the majority of subjects were native to the state of Nuevo Leon (74\%), 24 (27\%) were women. The average age of the subjects was 20 years and the median age of smoking initiation was 15 years. For this study, we selected the participants among those subjects who smoked more than five cigarettes in the last 3 days, since in a previous national survey, the range of consumption reported was 1 to 5 cigarettes per day [31]. Seventy-four subjects (84\%) indicated that they were daily smokers. Plasma cotinine was proportional to the number of cigarettes smoked (groups of cigarettes smoked: 1-5, 6-10, 11-20, >20; see Table 1). In addition, urinary and plasma cotinine levels show a positive correlation $(r=0.79, p<$ 0.0001 , and $r^{2}=0.50$; Fig. S1).

Table 2 shows the levels of each of the urinary nicotine metabolites expressed as a percentage of Total-Nic-Eq and after normalization with creatinine concentration. The major metabolite in smokers was $3 \mathrm{HC}$ ( $35 \%$ of Total-Nic-Eq) followed by 4HPBA (17\% of Total-Nic-Eq) $>3$ HC-Gluc (14\% of Total-Nic-Eq) $>$ cotinine $(9.5 \%$ of Total-Nic-Eq) $>$ nicotine- $N$ '-Oxide (7.6\% of Total-Nic-Eq) $>$ cotinine-Gluc (7.3\% of Total-Nic-Eq) $>$ nicotine $(4.3 \%$ of Total-Nic-Eq) $>$ cotinine- $N$-Oxide $(3.4 \%$ of Total-Nic-Eq) $>$ nicotine-Gluc (3.0\% of Total-Nic-Eq). For the glucuronides, the ratios of 3HC-Gluc were 1.9 and 4.6 times higher than those observed for cotinine-Gluc and nicotine-Gluc, respectively.
For the oxidation products, the cotinine- $N$-Oxide ratios were 2.2 times higher than that observed for nicotine- $N$ 'Oxide. The levels of $3 \mathrm{HC}$ and 4HPBA were 3.7- and 1.7fold higher, respectively, than those observed for cotinine. When smokers were stratified by nicotine metabolic ratio (NMR), using the previously reported threshold (slow metabolizers $<0.31$ and normal and fast metabolizers $\geq$ $0.31) 98.8 \%(n=87)$ of our smokers fell into the normal metabolizers category [32].

A linear correlation analysis of urinary metabolites normalized by creatinine levels was performed. Figure 2 shows a positive correlation between cotinine-Gluc vs cotinine- $N$ Oxide $(r=0.91 ; p<0.0001)$, cotinine-Gluc vs $3 \mathrm{HC}(r=$ $0.86 ; p<0.0001)$ and cotinine- $N$-Oxide vs $3 \mathrm{HC}(r=0.84$; $p<0.0001)$. Nicotine- $N$ '-Oxide was the least correlated with all metabolites $(r \leq 0.38)$.

A total of 10,283,992 readings were generated per NGS. 95\% had a score higher than Q30. 402 SNPs in 68 genes were identified, of which $260(65 \%)$ were found in exons. Of the variants identified, $71(27 \%)$ were missense variants. After filtering sequence data, 11 variants in $C Y P 2 A 6,14$ in CYP2B6, 4 in $U G T 2 B 7$ and 42 in UGT1A isoforms were available for association studies. The variants associated with different concentrations of nicotine metabolites were: $C Y P 2 A 6^{*} 12$ and rs 145014075 in the CYP2A6 gene, and rs12471326 in the UGT1A9 gene locus. These gene variants were in Hardy-Weinberg equilibrium, and the frequencies observed in our studied population are shown in Table 3.

The variants $C Y P 2 A 6^{*} 12$ and rs 145014075 , both in the CYP2A6 gene, were associated with altered levels of $3 \mathrm{HC}$ and nicotine, respectively. The variant $C Y P 2 A 6^{*} 12$ confers reduced enzyme activity as described above [30] and the variant rs 145014075 is a nonsense $\mathrm{G} / \mathrm{T}$ change generating a stop codon (Ser467Stop). The heterozygous genotype for $C Y P 2 A 6^{*} 12$ was associated with low levels of $3 \mathrm{HC}(p=$ 0.014 ), $30 \%$ of Total-Nic-Eq of cotinine-Gluc were observed in heterozygotes vs $39 \%$ in wild type homozygotes. The heterozygous genotype GT of rs145014075 variant was associated with high creatinine-adjusted levels of nicotine $(p=0.035)$ : $3 \%$ in heterozygotes vs $0.5 \%$ in wild type homozygotes (Fig. 3). No homozygotes for the mutant allele were found for either of these variants. The variant rs12471326 in the UGT1A9 gene was associated with high levels of cotinine-Gluc ( $p=0.030$ ), $9 \%$ of TotalNic-Eq of cotinine-Gluc was observed in heterozygotes vs $7 \%$ in wild type homozygotes (Fig. 3). No homozygotes for the mutant allele were found for this variant.

\section{Discussion}

This study showed that variants in $C Y P 2 A 6$ are associated to urinary levels of nicotine and $3 \mathrm{HC}$, while the UGTIA9 
Table 1 Demographic characteristics, smoking habits, and plasma cotinine levels in study subjects.
Table 2 Profile concentration of nicotine metabolites in urine of 88 smokers, expressed in percentage of Total-Nic-Eq and adjusted levels with milligrams of urinary creatinine.

\begin{tabular}{|c|c|c|c|c|}
\hline Characteristics & Values & $N(\%)$ & & $P$ \\
\hline$N$ total & & 88 & & \\
\hline \multirow[t]{3}{*}{ Origin } & Nuevo leon & 65 (74) & & \\
\hline & Coahuila & $9(10)$ & & \\
\hline & Others & 14 (16) & & \\
\hline \multirow[t]{2}{*}{ Gender } & Female & $24(27)$ & & $<0.0001^{*}$ \\
\hline & Male & $64(73)$ & & \\
\hline \multirow[t]{2}{*}{ Smoking daily } & Yes & $74(84)$ & & $<0.0001 *$ \\
\hline & No & 14 (16) & & \\
\hline Characteristics & Values & $N(\%)$ & $\begin{array}{l}\text { Cotinine (ng/mL) } \\
\text { Mean } \\
\text { (standard error) }\end{array}$ & $P$ \\
\hline \multirow{5}{*}{$\begin{array}{l}\text { Number of cigarettes } \\
\text { smoked in the last } \\
\text { three days }\end{array}$} & $1-5$ & $18(20)$ & $25(12.26)$ & $0.007 * *$ \\
\hline & $6-10$ & $19(22)$ & $78(22)$ & \\
\hline & $11-15$ & $17(19)$ & $63(24)$ & \\
\hline & $16-20$ & $8(9)$ & 139 (57) & \\
\hline & $>20$ & $26(30)$ & $131(24)$ & \\
\hline
\end{tabular}

$* P$-value from $\mathrm{Chi}^{2}$ test

$* * P$-value from ANOVA test

\begin{tabular}{lccccc}
\hline & \multicolumn{2}{l}{ \% de Total-Nic-Eq } & & & \multicolumn{2}{l}{$\begin{array}{l}\text { Creatinine-adjusted levels } \\
\text { (nmol/mg creatinine) }\end{array}$} \\
\cline { 2 - 3 } & Mean \pm ES $(95 \%$ CI $)$ & Range & & Mean \pm ES (95\% CI) & Range \\
\hline 3HC & $35 \pm 1.6(32-38)$ & $0.3-61$ & & $11 \pm 1.2(8.7-14)$ & $0.02-53$ \\
4HPBA & $17 \pm 2.1(13-21)$ & $1.6-89$ & & $3.9 \pm 0.5(3.0-4.7)$ & $0.02-22$ \\
3HC-Gluc & $14 \pm 0.7(14-16)$ & $0.1-30$ & & $4.4 \pm 0.6(3.2-5.6)$ & $0.004-38$ \\
Cotinine & $9.5 \pm 0.5(8.5-11)$ & $0.4-24$ & & $3.1 \pm 0.4(2.3-3.8)$ & $0.001-26$ \\
Nicotine- $N$ '-Oxide & $7.5 \pm 1.4(4.7-11)$ & $0.7-87$ & & $7.2 \pm 5.1(2.7-17)$ & $0.04-447$ \\
Cotinine-Gluc & $7.0 \pm 4.1(6.4-8.1)$ & $0.3-18$ & & $2.5 \pm 0.3(1.9-3.1)$ & $0.01-14$ \\
Nicotine & $4.0 \pm 6.6(3.0-5.7)$ & $0.1-47$ & & $1.2 \pm 0.1(0.9-1.5)$ & $0.001-6.2$ \\
Cotinine- $N$-Oxide & $3.0 \pm 1.6(3.1-3.7)$ & $0.1-8.2$ & & $1.1 \pm 0.1(0.8-1.3)$ & $0.00-6.1$ \\
Nicotine-Gluc & $3.0 \pm 2.5(2.5-3.5)$ & $0.2-16$ & & $1.1 \pm 0.2(0.8-1.5)$ & $0.8-1.4$ \\
\hline
\end{tabular}

variant is associated with urinary levels of cotinine-Gluc in young smokers from northeastern Mexico. The remaining variants in genes related to the nicotine metabolism failed to show associations. Regarding the CYP2A6 variants, Bloom et al. reported that the rs1137115 and rs28399435 were associated with low metabolism of nicotine in European Americans [33], but in our study no differences were observed among urinary levels of nicotine, cotinine and $3 \mathrm{HC}$ with these variants. The variant rs28399433 has been reported to be associated with smoking dependence in Mexican population [34], but no association was observed in our study at large. Nevertheless, when stratifying our samples according to their NMR, only the single sample that fell into the slow metabolizer category $(\mathrm{NMR}<0.31)$ presented with a heterozygous genotype for the rs28399433 variant. The low frequency of this variant among our studied population $(\mathrm{MAF}=0.13)$ might explain the lack of significant associations. CYP2A6 and CYP2B6 are responsible for 90 and $10 \%$ of the conversion of nicotine to cotinine, respectively [35]. CYP2A6 is responsible for $100 \%$ of the conversion of cotinine to $3 \mathrm{HC}$ [6]. Previous studies in cell lines and in vivo have shown that the CYP $2 A 6 * 12$ variant reduces the metabolism of coumarin in approximately $60 \%$ of subjects $[30,36]$. The $C Y P 2 A 6^{*} 12$ variant has been strongly associated with smoking status in Spaniards [37]. In the present study, the heterozygous genotype $C Y P 2 A 6 / 7$ was associated with low levels of $3 \mathrm{HC}$ as a percentage of the Total-Nic-Eq in young smokers. No 
differences of Total-Nic-Eq for cotinine were observed in $C Y P 2 A 6 / 6$ homozygotes and $C Y P 2 A 6 / 7$ heterozygotes. The $C Y P 2 A 6^{*} 12$ frequency in our population was low $(4 \%)$, close to those reported for Spaniard and Chinese populations (2.2 and $0 \%$, respectively) [30]. This variant can predispose to lower consumption of cigarettes [38], but we did not find significant differences in the number of consumed cigarettes in this study $(p=0.69)$.

The variant rs145014075 of the CYP2A6 gene was found in $3 \%$ of the subjects examined in this study. This variant causes a stop codon (Ser467Stop), but functional studies have not yet been reported for the enzymatic effects of the nonsense variant. This variant is reported in the 1000

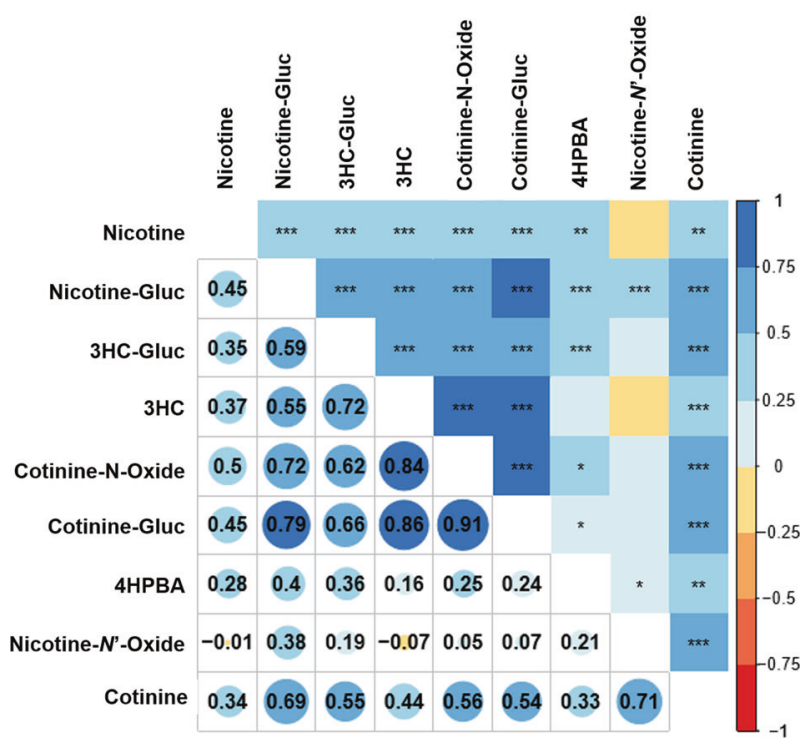

Fig. 2 Correlation Matrix of urinary nicotine and its eight major metabolites (nicotine, nicotine- $N$ '-oxide, nicotine-Gluc, cotinine, cotinine- $\mathrm{N}$-oxide, cotinine-Gluc, 3HC, 3HC-Gluc, and 4HPBA). Each cell in the table shows the correlation between two variables using the color code from the right side, where red indicates negative correlation values and blue indicate positive correlation values. The calculated values of the correlation coefficient are shown in the lower half at below the diagonal of the matrix. Pearson's product moment correlation coefficient are shown in the upper half above the diagonal of the matrix, where one, two or three asterisks indicate that the $p$ value was lower than $0.05,0.01$, and 0.001 , respectively. The empty cells indicate no correlation.
Genomes Project Database at frequencies of $4 \%$ and $2 \%$ in African American and European American populations, respectively. In the present study, this variant was associated with high creatinine-adjusted levels of nicotine, although no association was observed when examined as a percentage of Total-Nic-Eq. This association was not observed for the other analyzed variants. While this variant may reduce the activity of CYP2A6 and may be related to lower consumption of cigarettes, no association with the number of consumed cigarettes was found in the present study.

Regarding UGT2B7 gene variants, an important enzyme for the glucuronidation of $3 \mathrm{HC}$ [39], we did not find associations with glucuronides of nicotine metabolites. In the case of $U G T 2 B 17$, most of the variants were discarded after filtering with the parameters described above. We found an association between the levels of urinary cotinine-Gluc and the rs12471326 gene variant of UGT1A9. This intronic variant was found to be associated with high percentages of Total-Nic-Eq of cotinine-Gluc. There is a clinical study for this variant showing no differences in the in the postnatal metabolism of bilirubin, but no functional analyses in the nicotine metabolism have been reported [40].

Kaivosaari et al. reported that UGT1A9 did not exhibit any nicotine or cotinine glucuronidation activity in human liver microsomes (HLM) [41], and other studies showed that UGTs $2 \mathrm{~B} 10$ and $1 \mathrm{~A} 4$ were the major enzymes responsible for nicotine and cotinine glucuronidation [14]. However, Kuehl and Murphy studies in human liver microsomes suggested that UGT1A9 may also be involved in nicotine and cotinine glucuronidation, particularly contributing to a greater percentage of glucuronidation when nicotine levels are low [42]. The results of this report may be applied to the present study, since the cigarette consumption in the analyzed population is low (1-5 cigarettes per day) when compared with other populations (Latinos: 9.4 cigarettes per day; African Americans:11 cigarettes per day; Native Hawaiians: 15 cigarettes per day) [43].

The ethnicity and age of the studied subjects may explain the lack of associations among nicotine metabolites and variants in other UGTs involved in nicotine metabolism, like UGT2B17, UGT2B7, and UGT1A4, as reported in

Table 3 Allelic and genotypic frequencies of 88 subjects analyzed by NGS.

\begin{tabular}{|c|c|c|c|c|c|c|c|}
\hline Variants & Allele 1 & Allele 2 & Homozygous wild-type & Heterozygotes & Homozygous variant & MAF* $^{*}$ & $\operatorname{HWE}^{* *}(p)$ \\
\hline CYP $2 A 6 * 12$ & $\begin{array}{l}\text { CYP2A6 } \\
0.96\end{array}$ & $\begin{array}{l}\text { CYP2A6/7 } \\
0.04\end{array}$ & 0.92 & 0.08 & 0 & 0.04 & 0.67 \\
\hline $\begin{array}{l}\text { CYP2A6 } \\
\text { rs } 145014075\end{array}$ & G: 0.97 & $\mathrm{~T}: 0.03$ & 0.93 & 0.07 & 0 & 0.03 & 0.71 \\
\hline $\begin{array}{l}\text { UGT1A9 } \\
\text { rs12471326 }\end{array}$ & $\mathrm{T}: 0.91$ & C: 0.09 & 0.82 & 0.18 & 0 & 0.09 & 0.34 \\
\hline
\end{tabular}

*MAF minor allele frequency.

**HWE Hardy-Weinberg Equilibrium. 

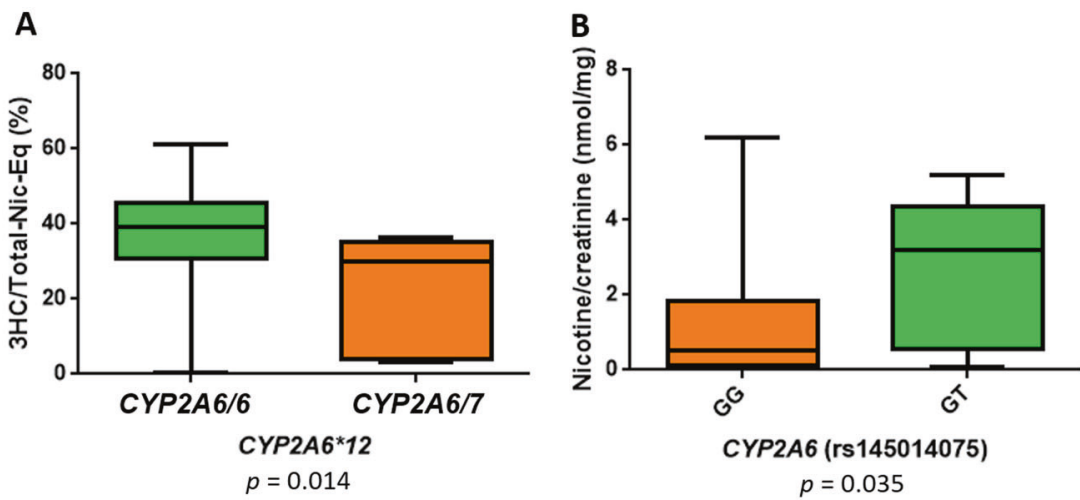

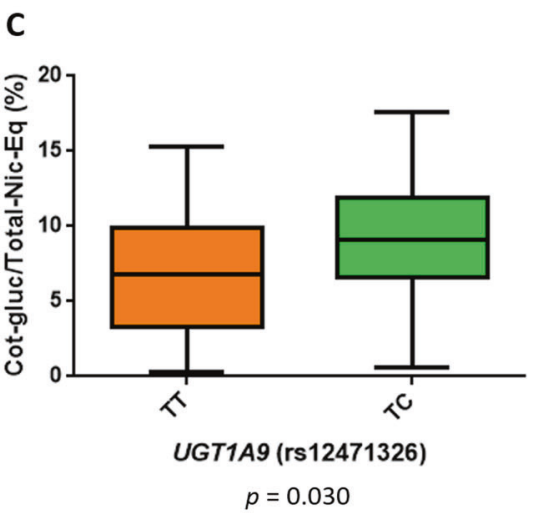

Fig. 3 Effect of variants on nicotine metabolite. a Genotypes $C Y P 2 A 6 / 6$ and $C Y P 2 A 6 / 7$ of the $C Y P 2 A 6$ gene vs percentage of $3 \mathrm{HC}$ analyte in the Total-Nic-Eq. b GG and GT genotypes of the rs145014075 variant of $C Y P 2 A 6$ vs creatinine-adjusted levels of nicotine. c TT and TC genotypes of the variant rs12471326 of the UGT1A9 gene vs percentage of cotinine-Gluc analyte in the Total-Nic-Eq. A

other studies [39, 44]. Expression of these UGTs may be related to the age, and most of the studies of nicotine metabolism has been performed in elderly subjects [45-47]. The expression of UGT1A9 is age-dependent. Miyagi et al. showed that the activity of UGT1A9 is higher in children than in adults and that this activity may be modulated by post-transcriptional and/or allosteric mechanisms in adults [48].

UGT2B10 is the major enzyme involved in both nicotine-Gluc and cotinine-Gluc formation and variants of this gene affect the glucuronidation of nicotine and cotinine $[12,45,49]$. We did not assess variants for UGT2B10 and/ or for the $F M O$ genes and this may affect the interpretation of glucuronidation rates for this study.

Allele frequencies of UGTIA variants differ among populations, as observed in the 1000 Genomes Project database. The allele C of rs12471326 variant in UGT1A9 described here was similar (9\%) to that observed for MXL (6\%), IBS (2\%), CEU (2\%), CHB (0\%), and YRI (7\%).

The levels of nicotine and its eight major metabolites were determined simultaneously in the urine of smokers in the present study. Interestingly, 4HPBA was the second highest metabolite as a percentage of Total-Nic-Eq (17\%). Chen et al. analyzed the same metabolites in the Caucasian population using the same methodology and found levels of 4HPBA that were almost 2-fold lower (\%Total-Nic-Eq $=8.9 \%)$ than the present study [15]. Rangia et al. reported 1.7-fold lower \%Total-Nic-Eq of 4HPBA (9.7\%) using a one-time urine collection [8], while Piller et al. reported 3.4-fold lower \%Total-Nic-Eq (5.0\%) in a 24-h urine specimens [50]. Subject age and/or ethnicity as well as level of cigarette consumption could all potentially be relevant factors influencing 4HPBA urinary levels in the population examined in the present study.
Mann-Whitney test for STATA (College station, TX) was used to make the comparisons of the genotypes and the levels of the metabolites. Metabolite levels are shown as percentage of analyte in the Total-Nic-Eq and creatinine-adjusted levels and are shown as the mean \pm standard error.

In conclusion, genetic variants rs145014075 and $C Y P 2 A 6 * 12$ in the $C Y P 2 A 6$ gene were associated with levels of phase I urinary nicotine metabolites and rs12471326 in UGTIA9 gene were associated with cotinine-Gluc metabolites levels of II phase nicotine metabolites in young Mexican smokers. These variants could be associated with addictive behaviors and with the development of diseases related to smoking in this population. Functional studies are necessary to define the participation of these genetic variants in the nicotine detoxification process. In addition, high levels of 4HPBA were found in the urine of the studied smokers. It has been proposed that CYP2A6 participates in the 2 '-hydroxylation of nicotine to produce 4HBPA [9], but this has not been fully evaluated. In the present study, several functional variants of CYP2A6 were analyzed, but none of these correlated with different levels of 4HPBA expressed in both, Total-Nic-Eq or creatinine-adjusted levels. These data are consistent with possibility that other enzymes in addition to CYP2A6 are involved in 4HPBA formation.

Studies characterizing the enzymes involved in 4HPBA formation should be performed to better define the possible health risks related to this metabolite.

Acknowledgements We thank all of the subjects who were willing to participate in this study and the authorities of the Universidad Autonoma de Nuevo Leon. These studies were funded by the grants CONACyT-Mexico S0008-2014-1 and CONACyT-Mexico 2016-013262 to G. Borrego-Soto, a grant from the National Institutes of Health, National Institutes of Environmental Health Sciences [Grant R01-ES025460] to PL, a grant from the Fulbright-Garcia Robles Program and a CONACyT dissertation grant to YXP-P, and a grant from the Health Sciences and Services Authority of Spokane, WA [Grant WSU002292] to the Washington State University College of Pharmacy and Pharmaceutical Sciences. 


\section{Compliance with ethical standards}

Conflict of interest The authors declare that they have no conflict of interest.

Publisher's note Springer Nature remains neutral with regard to jurisdictional claims in published maps and institutional affiliations.

Open Access This article is licensed under a Creative Commons Attribution 4.0 International License, which permits use, sharing, adaptation, distribution and reproduction in any medium or format, as long as you give appropriate credit to the original author(s) and the source, provide a link to the Creative Commons license, and indicate if changes were made. The images or other third party material in this article are included in the article's Creative Commons license, unless indicated otherwise in a credit line to the material. If material is not included in the article's Creative Commons license and your intended use is not permitted by statutory regulation or exceeds the permitted use, you will need to obtain permission directly from the copyright holder. To view a copy of this license, visit http://creativecommons. org/licenses/by/4.0/.

\section{References}

1. World Health Organization. MPOWER. Un plan de medidas para hacer retroceder la epidemia de tabaquismo, Vol 39. 2008.

2. World Health Organization. WHO Global Report: Mortality Attributable To Tobacco. Who Global Report. 2012.

3. Olguín VI, Renner DG, Cwilich RG, Alexander JA, Ramírez GM, Schneeweiss LG, et al. Características demográficas del cáncer de pulmón y su asociación con la exposición a humo de leña en la población mexicana. Médicos la Asoc Médica del Cent Médico ABC. 2018;63:188-93.

4. Tanner J, Chenoweth MJ, Tyndale RF. Pharmacogenetics of nicotine and associated smoking behaviors. Curr Top Behav Neurosci. 2015;23:37-86.

5. Mattes W, Yang X, Michael O, Richter RP, Donna LM. Biomarkers of tobacco smoke. Adv Clin Chem. 2014;67:1-45.

6. Tanner J, Novalen M, Jatlow P, Huestis M, Murphy S, Kaprio J, et al. Nicotine metabolite ratio (3-hydroxycotinine/cotinine) in plasma and urine by different analytical methods and laboratories: Implications for clinical implementation. Cancer Epidemiol Biomark Prev. 2015;24:1239-46.

7. Perez-Paramo YX, Chen G, Ashmore JH, Watson CJW, Nasrin S, Adams-Haduch $\mathrm{J}$, et al. Nicotine-N'-oxidation by flavin monooxygenase enzymes. Cancer Epidemiol Biomark Prev. 2019;28:311-20.

8. Rangiah K, Hwang WT, Mesaros C, Vachani A, Blair IA. Nicotine exposure and metabolizer phenotypes from analysis of urinary nicotine and its 15 metabolites by LC-MS. Bioanalysis. 2011;3:745-61.

9. Hecht SS, Hochalter JB, Villalta PW, Murphy SE. 2'-Hydroxylation of nicotine by cytochrome P450 2A6 and human liver microsomes: formation of a lung carcinogen precursor. Proc Natl Acad Sci USA. 2000;97:12493-7.

10. Nakajima M, Yokoi T. Interindividual variability in nicotine metabolism: c-oxidation and glucuronidation. Drug Metab Pharmacokinet. 2005;20:227-35.

11. Benowitz NL, St. Helen G, Dempsey DA, Jacob P, Tyndale RF. Disposition kinetics and metabolism of nicotine and cotinine in African American smokers. Pharmacogenet Genomics. 2016;26:340-50.

12. Patel YM, Stram DO, Wilkens LR, Park SSL, Henderson BE, Le Marchand L, et al. The contribution of common genetic variation to nicotine and cotinine glucuronidation in multiple ethnic/racial populations. Cancer Epidemiol Biomark Prev. 2015;24:119-27.

13. Bloom AJ, Von Weymarn LB, Martinez M, Bierut LJ, Goate A, Murphy SE. The contribution of common UGT2B10 and CYP2A6 alleles to variation in nicotine glucuronidation among european americans. Pharmacogenet Genomics. 2013;23:706-16.

14. Chen G, Giambrone NE, Lazarus P. Glucuronidation of trans-3'hydroxycotinine by UGT2B17 and UGT2B10. Pharmacogenet Genomics. 2012;29:997-1003.

15. Chen G, Giambrone NE, Dluzen DF, Muscat JE, Berg A, Gallagher CJ, et al. Glucuronidation genotypes and nicotine metabolic phenotypes: importance of functional UGT2B10 and UGT2B17 polymorphisms. Cancer Res. 2010;70:7543-52.

16. Chen G, Blevins-Primeau AS, Dellinger RW, Muscat JE, Lazarus P. Glucuronidation of nicotine and cotinine by UGT2B10: loss of function by the UGT2B10 codon 67 (Asp>Tyr) polymorphism. Cancer Res. 2007;67:9024-9.

17. Ross KC, Gubner NR, Tyndale RF, Hawk LW, Lerman C, George $\mathrm{TP}$, et al. Racial differences in the relationship between rate of nicotine metabolism and nicotine intake from cigarette smoking. Pharm Biochem Behav. 2016;148:1-7.

18. Wassenaar CA, Ye Y, Cai Q, Aldrich MC, Knight J, Spitz MR, et al. CYP2A6 reduced activity gene variants confer reduction in lung cancer risk in African American smokers-findings from two independent populations. Carcinogenesis. 2015;36:99-103.

19. Fujieda M, Yamazaki H, Saito T, Kiyotani K, Gyamfi MA, Sakurai M, et al. Evaluation of CYP2A6 genetic polymorphisms as determinants of smoking behavior and tobacco-related lung cancer risk in male Japanese smokers. Carcinogenesis. 2004;25:2451-8.

20. Sinaga BYM, Mutiara E, Soeroso NN, Zain-Hamid R, Syahruddin E, Tann G, et al. The role of CYP2A6 genetic polymorphism in nicotine dependence and tobacco consumption among bataknese male smokers. Open Access Maced J Med Sci. 2018;6:864-6.

21. Pérez-Rubio G, López-Flores LA, Ramírez-Venegas A, Noé-Díaz V, García-Gómez L, Ambrocio-Ortiz E, et al. Genetic polymorphisms in CYP2A6 are associated with a risk of cigarette smoking and predispose to smoking at younger ages. Gene. 2017;628:205-10.

22. Guillemette C, Hovington H, Nguile-Makao M, Harvey M, Bergeron $\mathrm{A}$, Caron A, et al. Phase II drug-metabolizing polymorphisms and smoking predict recurrence of non-muscle-invasive bladder cancer: a gene-smoking Interaction. Cancer Prev Res. 2015;9:189-95.

23. Angstadt AY, Berg A, Zhu J, Miller P, Hartman TJ, Lesko SM, et al. The effect of copy number variation in the phase II detoxification genes UGT2B17 and UGT2B28 on colorectal cancer risk. Cancer. 2013;119:2477-85.

24. Cui X, Lu X, Hiura M, Omori H, Miyazaki W, Katoh T. Association of genotypes of carcinogen-metabolizing enzymes and smoking status with bladder cancer in a Japanese population. Environ Health Prev Med. 2013;18:136-42.

25. Tyndale RF, Ahluwalia JS, Zhou Q, Benowitz NL, Zhu AZX, Cox LS. Variation in trans-3'-hydroxycotinine glucuronidation does not alter the nicotine metabolite ratio or nicotine intake. PLoS ONE. 2013;8:e70938.

26. ENCODAT. Consumo de tabaco, exposición de segunda mano y estrategias de control en México. 2016;1-8.

27. Jamal A, Phillips E, Gentzke AS, Homa DM, Babb SD, King BA, et al. Current Cigarette Smoking Among Adults-United States, 2016. Morb. Mortal Wkly Rep. 2018;67:53-9.

28. Pulvers K, Scheuermann TS, Romero DR, Basora B, Luo X, Ahluwalia JS. Classifying a smoker scale in adult daily and nondaily smokers. Nicotine Tob Res. 2014;16:591-9.

29. López-Flores LA, Pérez-Rubio G, Ramírez-Venegas A, Ambrocio-Ortiz E, Sansores RH, Falfán-Valencia R. Data on 
polymorphisms in CYP2A6 associated to risk and predispose to smoking related variables. Data Brief. 2017;15:86-91.

30. Oscarson M, McLellan R, Asp V, Ledesma M, Bernal Ruiz ML, Sinues B, et al. Characterization of a novel CYP2A7/CYP2A6 hybrid allele (CYP2A6*12) that causes reduced CYP2A6 activity. Hum Mutat. 2002;20:275-83.

31. Salomón M, Woldenberg C, Igor L, Valencia $\mathrm{R}$ Encuesta Nacional de Adicciones. 2011; 1-89.

32. Lerman C, Schnoll RA, Hawk LW Jr, Cinciripini P, George TP, Wileyto EP, et al. Use of the nicotine metabolite ratio as a genetically informed biomarker of response to nicotine patch or varenicline for smoking cessation: a randomised, double-blind placebo-controlled trial. Lancet Respir. 2015;2600:1-8.

33. Bloom J, Hinrichs AL, Wang JC, Von Weymarn LB, Kharasch ED, Bierut LJ, et al. The contribution of common CYP2A6 alleles to variation in nicotine metabolism among European Americans. Pharmacogenet Genomics. 2013;23:706-16.

34. Svyryd Y, Ramírez-Venegas A, Sánchez-Hernández B, AguayoGómez A, Luna-Muñoz L, Arteaga-Vázquez J, et al. Genetic risk determinants for cigarette smoking dependence in Mexican mestizo families. Nicotine Tob Res. 2016;18:620-5.

35. Al Koudsi N, Tyndale RF. Hepatic CYP2B6 is altered by genetic, physiologic, and environmental factors but plays little role in nicotine metabolism. Xenobiotica. 2010;40:381-92.

36. Al Koudsi N, Hoffmann EB, Assadzadeh A, Tyndale RF. Hepatic CYP2A6 levels and nicotine metabolism: impact of genetic, physiological, environmental, and epigenetic factors. Eur J Clin Pharm. 2010;66:239-51.

37. Girard N, Lou E, Azzoli CG, Reddy R, Robson M, Harlan M, et al. Analysis of genetic variants in never-smokers with lung cancer facilitated by an Internet-based blood collection protocol: a preliminary report. Clin Cancer Res. 2010;16:755-63.

38. Schoedel K, Hoffmann EB, Rao Y, Sellers EM, Tyndale RF. Ethnic variation in CYP2A6 and association of genetically slow nicotine metabolism and smoking in adult Caucasians. Pharmacogenetics. 2004;14:615-26.

39. Wassenaar CA, Conti DV, Das S, Chen P, Cook EH, Ratain MJ, et al. UGT1A and UGT2B genetic variation alters nicotine and nitrosamine glucuronidation in European and African American smokers. Cancer Epidemiol Biomark Prev. 2015;24:94-104.
40. Weaver A, Hanchard NA, O'Kane DJ, Karon BS, Cook W, Skierka J, et al. UGT1A1 sequence variants and bilirubin levels in early postnatal life: a quantitative approach. BMC Med Genet. 2011;22:12-57.

41. Kaivosaari S, Toivonen P, Hesse LM, Koskinen M, Court MH, Finel M. Nicotine glucuronidation and the human UDPglucuronosyltransferase UGT2B10. Mol Pharm. 2007;72:761-8.

42. Kuehl GE, Murphy SE. N-glucuronidation of nicotine and cotinine by human liver microsomes and heterologously expressed UDP-glucuronosyltransferases. Drug Metab Dispos. 2003;31:1361-8.

43. Wang H, Park SL, Stram DO, Haiman CA, Wilkens LR, Hecht $\mathrm{SS}$, et al. Associations between genetic ancestries and nicotine metabolism biomarkers in the multiethnic cohort study. Am J Epidemiol. 2015;182:945-51.

44. Nakajima M, Tanaka E, Kwon JT, Yokoi T. Characterization of nicotine and cotinine $\mathrm{N}$-glucuronidations in human liver microsomes. Drug Metab Dispos. 2002;30:1484-90.

45. Murphy SE, Park S-SL, Thompson EF, Wilkens LR, Patel Y, Stram DO, et al. Nicotine N-glucuronidation relative to $\mathrm{N}$ oxidation and C-oxidation and UGT2B10 genotype in five ethnic/ racial groups. Carcinogenesis. 2014;35:2526-33.

46. Lessov-Schlaggar CN, Benowitz NL, Jacob P, Swan GE. Genetic influences on individual differences in nicotine glucuronidation. Twin Res Hum Genet. 2009;12:507-13.

47. Cheheltani R, Ezzibdeh RM, Chhour P, Pulaparthi K, Kim J, Jurcova $\mathrm{M}$, et al. Genome-wide association study of a nicotine metabolism biomarker in African American smokers: impact of chromosome 19 genetic influences. Addiction. 2017;113:87-97.

48. Miyagi SJ, Milne AM, Coughtrie MWH, Collier AC. Neonatal development of hepatic UGT1A9: Implications of pediatric pharmacokinetics. Drug Metab Dispos. 2012;40:1321-7.

49. Berg JZ, von Weymarn LB, Thompson EA, Wickham KM, Weisensel NA, Hatsukami DK, et al. UGT2B10 genotype Influences nicotine glucuronidation, oxidation, and consumption. Cancer Epidemiol Biomark Prev. 2001;19:1423-31.

50. Piller M, Gilch G, Scherer G, Scherer M. Simple, fast and sensitive LC-MS/MS analysis for the simultaneous quantification of nicotine and 10 of its major metabolites. J Chromatogr B Anal Technol Biomed Life Sci. 2014;1:951-2. 